\title{
Ethical aspects regarding publications
}

Ethical aspects of scientific publications have kept biomedical journal editors busy and concerned given the increased number of rejections due to unethical conduct in published articles. $^{1}$

Since 1979, biomedical journal editors have supported their work based on the Uniform Requirements for Manuscripts Submitted to Biomedical Journals. ${ }^{2}$ These guidelines are the result of a meeting among editors of the most outstanding medical journals held in Vancouver in 1978 in order to improve the quality of publications and facilitate peer-review.

These guidelines were updated in 2013 under the name Recommendations for the Conduct, Reporting, Editing, and Publication of Scholarly Work in Medical Journals. ${ }^{3}$ Best practice and ethical standards were reviewed to help editors and authors create and distribute biomedical research in an accurate, clear and unbiased manner, respecting ethical principles that govern scientific research and publication. In addition, these recommendations are aimed at providing useful insight for the media, patients and their families, and general readers.

These guidelines are not mandatory, but they are strongly recommended for scientific journals that adhere to such principles. It has been encouraged that these recommendations are included in the Instructions for authors. The fact that 10 out of the 16 pages that make up these recommendations are devoted to ethical aspects is not a minor detail.

The Committee on Publication Ethics (COPE) was established in 1997 and is presently made up of more than 9000 peer-reviewed scientific journal editors. The COPE issued best practice guidelines and a code of conduct expected to be shared by the international scientific community. Several algorithms have also been developed to guide editors dealing with ethical conflicts. ${ }^{4}$

Editors should ensure that the following ethical aspects are met: informed consent provided by patients to use their data; study approval by an institutional ethics committee; and ethical research conduct (procedures, treatments).

National law $n^{\circ} 26529$, Patient rights, medical record and informed consent, establishes a right to confidentiality: every person involved in the preparation or handling of clinical documents or with access to them shall keep them confidential except as otherwise stated by a competent legal authority or as per the patient's authorization.
The Instructions for authors of Archivos Argentinos de Pediatría indicate that, for clinical case reports, the patient or his/her representative should be asked to provide their informed consent for the publication of any personal information (medical record data, images, and any other information regarding the patient), and this should be clearly stated in the manuscripts submitted to our journal. This requirement will be valid as of the first issue of 2015 .

One of the most important obligations of editors is that, if they suspect any unethical conduct in the manuscripts submitted or already published, they should act on it. Acting is not limited exclusively to rejecting or revoking an article; editors should ask authors or their institutions for an explanation in order to discourage such behavior and create awareness on ethical principles.

In the past few months, here at Archivos Argentinos de Pediatría such conflicts have often encountered and it makes us wonder what the reason for this unfortunate increase is.

The most important concept in the editorial process is good faith. Editors have to rely on authors' truthfulness and on reviewers' objectivity. Authors trust their editors' and reviewers' impartiality.

Based on this basic assumption, conflicts may be the result of ignoring ethical principles regarding publications or that, even though authors attempt to respect them, sometimes mild or severe weaknesses lead them to act in a questionable manner.

For example, unjustified authorship, not declaring a conflict of interest, duplicate submission or manuscript publication, research data fragmentation, and redundancy. The most serious unethical conducts are plagiarism and data falsification.

It is common to see professionals who did not actively participate in the original research idea, publication, bibliographic search or writing, listed as "authors" just because they offered their moral support during the research or read the final manuscript. Sometimes, this is openly stated. On other occasions, authors are said to have had an active participation but editors' suspicion is raised when a prestigious professional who claims to have read the manuscript is listed as an author in the last place, and there is something he would have never accepted if he had actually read the article. 
A desire to be listed as part of a research work may be due to a need to make their resume more attractive or to maintain a certain standing in their workplace. Far from improving reputation, such conduct only impairs it.

It is a matter of common sense to report whether professional judgment regarding the primary interest (patients' well-being or research validity) may have been influenced by a secondary interest (personal benefit, competitiveness or favoritism). If a possible conflict of interest is suspected by the reader, it should be regarded as if there was an actual conflict of interest. Without a doubt, transparency is the key. It is better to discuss it than to be questioned about it.

Duplicate submission of manuscripts occurs when the same manuscript is sent to several journals so as to gain time should it be rejected by any of the journals. It also refers to sending an article already published in a small circulation journal to other with a larger circulation. Journals indexed in Medline tend to attract such duplications because they reach a wider audience, especially when also published in English.

Reasons for preventing information duplication are respect for readers' good faith, who believe to be reading an original article, the relevance of avoiding medical case distortion, and prevention of duplication of review efforts. Information should only be widely disseminated when it is relevant for public health and includes a clarification about the original source.

Redundant publications repeat concepts or data regarding the same patients, and have at least one author in common. Subtle modifications in the order that authors are listed or in the title wording and not mentioning a previous publication both suggest an intent of concealment.

In the case of plagiarism, authors copy fragments from a different article verbatim or make minimum alterations, such as changing word order, but fail to mention the original author or to quote the author and cite the source in the bibliographic references. Reviewers are specialists in this matter and tend to detect such attitudes. Feeling like something has "already been read" leads them to find out that a manuscript is an identical match for a book chapter on the same specialty or other published article. At present, there is software developed to detect plagiarism.

In any case, transparency helps to make the right decisions. When concerns arise around transparency, conflicts appear. Authors should clearly mention any previous publication of the material sent to a scientific journal, either total or partial, or even if it focuses on a different aspect or aimed at a different group of readers. It is advisable that the submission is accompanied by any previous publication so that editors can judge for themselves whether such different or novel aspects warrant a new publication. However, if authors do not want such duplication to be noticed, they will not clearly mention such previous publication.

Authors may allege that they were unaware or inexperienced, or justify themselves in that the publication rules do not clearly deal with this specific subject. Unawareness does not waive responsibilities, and when in doubt, authors should resolve it before submitting their manuscript.

To sum up, when authors are confronted with an ethical problem, they sometimes respond in a satisfactorily and respectful manner, thus allowing editors to either end or continue with the review process, as applicable. Sometimes, authors' replies show anger, annoyance, disbelief and confrontation. This should be examined from a sociologic perspective so as to understand the different behaviors of our society, our natural trend to disrespect rules or to make flexibility the only shape for all of our behaviors.

Ethical standards establish that the corresponding editorial decision to make in these cases is rejecting the manuscript upon providing a reasonable explanation so as to disseminate such ethical principles.

Norma Rossato, M.D. Associate Editor

http:/ /dx.doi.org/10.5546/aap.2014.eng.490

\section{REFERENCES}

1. Singh HP, Mahendra A, Yadav B, Singh H, et al. A comprehensive analysis of articles retracted between 2004 and 2013 from biomedical literature - a call for reforms. J Tradit Complement Med 2014;4(3):136-9.

2. Comité Internacional de Editores de Revistas Médicas. Requisitos de uniformidad para manuscritos enviados a revistas biomédicas: redacción y preparación de la edición de una publicación biomédica. Barcelona: Universitat Autónoma de Barcelona; 2011. [Available at: http:/ / www. metodo.uab.cat/docs/Requisitos_de_Uniformidad_Ejemplos_de_referencias.pdf]. [Accessed on: August 27, 2014].

2. International Committee of Medical Journal Editors. Recommendations for the Conduct, Reporting, Editing, and Publication of Scholarly Work in Medical Journals. Philadelphia: ICMJE; 2013. [Available at: http:/ /www.icmje. org/recommendations/]. [Accessed on: August 27, 2014].

4. Committee on Publication Ethics. All-flowcharts-Spanish. UK: COPE; 2008. [Available at: http:/ / publicationethics. org/files/All_Flowcharts_Spanish_0.pdf]. [Accessed on: August 27, 2014]. 